\title{
Ensino de Filosofia e responsabilidade pelo mundo: aproximações (in) adequadas entre Paulo Freire e Hannah Arendt
}

\author{
Teaching Philosophy and responsibility \\ for the world: (in) appropriate approaches \\ between Paulo Freire and Hannah Arendt
}

Ricardo George de Araújo Silva

Orcid: https://orcid.org/0000-0003-1954-1395 - E-mail: ricardogeo11@yahoo.com.br

\begin{abstract}
RESUMO
O presente texto pretende discutir uma aproximação entre Hannah Arendt e Paulo Freire. Esta aproximação não nega as especificidades de cada autor e as fronteiras que demarcam seus interesses como pensadores. Assim, centramos a aproximação naquilo que nos parece ser uma interseção entre ambos, qual seja: uma noção de educação como responsabilidade pelo mundo e, neste contexto, discutiremos a relevância do ato de ensinar e do ensino de filosofia em específico. Tomamos como metodologia a exegese textual.
\end{abstract}

Palavras-chave: Ensino de Filosofia. Educação. Mundo. Responsabilidade.

\begin{abstract}
The present text intends to discuss an approach between Hannah Arendt and Paulo Freire. This approach doesn't deny the specificities of each author and the limits that demarcate their interests as thinkers. Then, we centralize the approach in that what we seem to be an intersection between both, that it is: a notion of education as responsibility for the world and, in this context, we're going to talk over the relevancy of the teaching act of teaching philosophy in specific. We take as methodology the textual exegesis.
\end{abstract}

Keywords: Teaching of philosophy. Education. World. Responsibility. 
Dedico esse texto aos meus filhos Rafael e Renata

por me fazerem amar a educação e o mundo!

\section{Introdução}

O Ensino de Filosofia está presente no ocidente desde os gregos. Todavia, o ato de ensinar não existiu sem a desconfiança dos espaços na qual adentrou. Talvez, a maior marca que definia o ensino de filosofia como ensino suspeito, como ensino de turbulência, tenha sido a condenação de Sócrates (PLATÃO, 1999, p. 67).

Nesta direção, temos que o ensino de filosofia emergiu na história do ocidente como uma prática de questionamento do status quo. O ensino de filosofia revelou-se como prática inconformada, questionadora e revolucionária. Todavia, também como reflexão e responsabilidade pelo mundo. $O$ ensino de filosofia, não emergiu com fim em si mesmo, ao contrário, visou o mundo e sua perfectibilidade. Pensar o mundo e suas relações em cada época implicou em responsabilizar-se por este. Assumir o ethos da transmissibilidade a outras gerações redundou em assumir o ethos do mundo, em sua perspectiva do bem maior, da justiça e da felicidade pública.

Essa marca inconteste de ser um pensamento incômodo, na medida em que retira da zona de conforto as ditas verdades de cada época fazem do ensino de filosofia um ensino de vanguarda. O bom exemplo disso em nossa época são as posições de Jacques Derrida, que ao participar das discussões sobre o ensino de filosofia na França, chegou a asseverar que o ethos a ser assumido no ensino de filosofia ocorre na direção do direito universal, nas suas palavras "o direito à filosofia para todos" ${ }^{1}$. Nos tempos hodiernos, nenhuma forma de ensino pode ser privilégio de poucos, muito menos o ensino de filosofia. Embora, de alguma forma ela seja lançada na perspectiva de um ensino de massas. ${ }^{2}$

O ensino de filosofia deve se confundir com o próprio filosofar. Pelo contrário, não passará de pura linearidade conceitual, o que nos acostumamos a chamar de história da filosofia, que tem sua relevância, todavia, apresentada de forma estanque e isolada do tempo presente é, a nosso ver, infrutífera. Sendo assim, o ensino deve ser vivo, por ser presente.

Assumir o ensino vivo implica promover a reflexão dos conceitos da tradição com o tempo presente, de alguma forma eles são luzes para nossa época. Levam-nos a pensar o que estamos fazendo ou nas palavras de Arendt (2009, p. 147) nos indaga:"o que nos faz pensar" nos colocando, assim, em uma via de compreensão do mundo.

Desse modo, quando o ensino se dissocia da vida dos homens e mulheres de cada época, ele assume sua fantasmagoria, e transforma-se num vazio especulativo. Na contra mão dessa postura, temos o ensinamento pedagógico de Platão de retornar à caverna ${ }^{3}$. Isto implica

\footnotetext{
1 O Filósofo Francês se engajou nessas discussões em seu país e de modo especial proferiu palestras e escreveu sobre o tema. Rodrigo (2009, p. 10) em nota de rodapé, destaca que: "Du droit à la philosophie foi de início o título de um seminário de que participou Derrida em 1984; o mesmo título foi mantido para nomear a obra publicada pelo autor em 1990. Nesse livro, Derrida reúne vários e nsaios e alguns trabalhos apresentados em eventos científicos sobre a temáticas relacionadas ao ensino e à identidade da filosofia."

2 Embora relevante, o tema do ensino de massas, não nos ocuparemos aqui dessa problemática, por não representar nosso objetivo no texto.

3 Cf. (PLATÃO, 1980, 516DE). No livro VII o retorno a caverna implica a reflexão sobre a importância de não ficar reduzido à contemplação e, sobretudo, assumir o risco em meio à contradição do mundo. Ensinar sempre é um risco e, sempre será, um incômodo. Uma educação que não incomode não é digna de ser chamada de ensino para o pensar. A filosofia, por excelência, é um ensino para o pensar.
} 
"sujar as mãos", correr riscos, ao deliberar com quem está filiado a posições arbitrárias e, as tomam sem o menor exame. Isto é, nos conduz à vida comum, para deliberarmos sobre ela. Quem ensina convida e provoca o pensar e, junto com ele, mobiliza o agir.

A tradição do saber elaborado no ocidente se moveu na franja que vai da apreensão conceitual a otimização do homem em meio as suas realizações na sociedade. $O$ ensino de filosofia, na grande maioria dos pensadores, guardou para si a missão de melhorar o ser humano para otimizar o mundo. Parecem-nos perspectivas exemplares disso a visão de Platão, que via na sabedoria a assertividade da vida justa e a de Rousseau que vislumbrou no Emílio o paradigma de cidadão. Em ambos os casos, temos aqui o papel do ensino centrado no indivíduo com vistas ao que ele pode fazer no mundo. Neste contexto, visam-se as perspectivas, da autonomia, da ação e da responsabilidade pelo mundo, via uma deliberação pautada na liberdade.

Dito isto, entendemos que os trilhos da tradição chegam à contemporaneidade e expressam as obras de pensadores como Hannah Arendt e Paulo Freire, entre outros, sobretudo, as dimensões do agir, da liberdade, da autonomia, como marcas de um ensino de filosofia pautado na responsabilidade pelo mundo. Embora seja evidente a fronteira entre os pensadores em questão, é possível, entre algumas inadequações, encontrarmos aproximações pertinentes entre eles, considerando o ensino e seu cuidado com o mundo.

Nosso percurso, irá dessa maneira, apresentar em linhas gerais, a visão de Paulo Freire sobre o ato de ensinar e sua relação com o mundo e como isto implica em reflexão e ação no processo de qualquer abordagem de aprendizagem. Durante a abordagem destacaremos como o ensino de filosofia implica nesse cuidado com o mundo.

Nesta direção destacaremos a visão de Freire sobre educação e como ele entende este processo educacional ligado a responsabilidade pelo mundo. Faremos isso considerando que Freire foi fortemente influenciado por leituras de pensadoras e pensadores da filosofia, por ele mesmo apontado, tais como: Arendt, Marcuse, Marx, M. Ponty, Gramsci, Sartre, entre outros. (Cf. FREIRE, 1992, p. 20).

Num segundo momento iremos destacar a reflexão de Arendt sobre a educação e a responsabilidade com o mundo. Buscaremos mostrar que a noção de educação na autora se dá via o que ela chamou de amor-mundit.

Por fim, na trama do argumento buscaremos pôr em evidência a relevância das categorias chaves para nosso propósito aqui, tais como; Educação, mundo, ação, liberdade e responsabilidade.

\section{Paulo freire e o ensinar comprometido com o mundo}

Pensar com Paulo Freire implica pensar o que fazemos enquanto educadores. Em última instância, se trata de uma reflexão sobre a prática. O pensador pernambucano alude a uma educação para a autonomia (FREIRE, 1999, p. 65) na qual o ser livre e capaz de deliberações, ocupa o espaço da política e do ensino enquanto espaços privilegiados de ação.

O agir em Paulo Freire é alimentado por uma utopia. Cabe esclarecer que utopia no educador não se reduz a um sonho irrealizável, como uma forma ingênua de algo inalcançável. Sonho sim, inalcançável, não. Utopia em Paulo Freire está mais próximo daquilo que pode ser e

\footnotetext{
4 Para Vanessa o Amor mundi não pode ser ensinado e se revela na prática do professor com o mundo [...]. Segundo a comentadora a educação é uma aposta cujo resultado não temos controle, por isso mesmo nos compete fazer o melhor. (CF. ALMEIDA, 2009, p. 93). Este fazer melhor, nós entendemos como responsabilidade pelo mundo. Assim, o melhor a fazer sempre estará pautado pelo interesse público, pela justiça, pela liberdade, pelo direito a pertencer a uma comunidade política e dela gozar de direitos. Enfim, o direito a uma felicidade pública.
} 
ainda não é, por exemplo, o sonho de um mundo justo. Suas palavras denunciam isso quando trata da indignação que sente diante das injustiças do mundo: assevera ele: "daí meu tom de raiva, legítima raiva, que envolve o meu discurso quando me refiro ás injustiças a que são submetidos os esfarrapados do mundo" (FREIRE, 1999, p. 15). Ele tá pensando e agindo via uma transformação de uma situação injusta. Assim, como veremos pressupõe luta e não acomodação em relação a tal situação. Não há aqui a ilusão da mudança sem mobilização. A utopia se constrói na luta, na resistência e na esperança.

O ensino para Paulo Freire nunca foi apenas método, a educação nunca foi apenas teoria. Para ele, estes representavam ações no mundo. Ações que consideravam a defesa de algo maior do que apenas alfabetizar. Sim, alfabetizar é fundamental, todavia, não se esgota no ato do letramento. É preciso lê o mundo, transformar o mundo, comprometer-se com o mundo. E, esse comprometimento tem lado, tem posição, é o lado dos mais fracos, dos desvalidos da terra, dos subalternos. Como ele nos esclarece: "o meu ponto de vista é o dos "condenados da terra", dos excluídos" (FREIRE, 1999, p. 16).

Nessa direção concordamos com Fiori $(2005$, p. 7) quando ressalva que "Paulo Freire é um pensador comprometido com a vida: não pensa ideias, pensa a existência". Assim, ao se deparar como o mundo se compromete com ele e visa ser seu habitante em plenitude, o que implica se opor a toda forma de injustiça, de horror, de terror de domínio total. Tem em mente e em movimento uma educação libertadora. Nesta medida, "a educação libertadora é incompatível com uma pedagogia que, de maneira consciente ou mistificada, tem sido prática de dominação" (FIORI, 2005, p. 7).

A postura de ensino de Paulo Freire é, portanto, política e pedagógica. Política, pois, compromete-se com o mundo e com a liberdade, e pedagógico, pois visa à autonomia do ser humano frente a todo saber elaborado. Assim, podemos afirmar que sua proposta não se reduz ao letramento, pois, é também e, ousamos afirmar, tem sua centralidade em um ato político, na medida em que visa à liberdade dos oprimidos.

Entende o pensador que a busca pela liberdade implica na ausência desta, sua efetivação precisa acontecer no ato de ser livre e como busca permanente. As formas de opressão sejam elas via o autoritarismo das armas, sejam as armadilhas do jogo de consumo do mercado, que nos iludem e nos aprisionam, precisam ser permanentemente enfrentadas. Em Freire a liberdade emerge como categoria analítica, mas, sobretudo, como postura orientadora da práxis e como conquista em uma luta permanente. Nas palavras do pensador:

A liberdade, que é uma conquista, e não uma doação, exige uma permanente busca. Busca permanente que só existe no ato responsável de quem a faz. Ninguém tem liberdade para ser livre: pelo contrário, luta por ela precisamente porque não a tem. Não é também a liberdade um ponto ideal, fora dos homens, ao qual inclusive eles se alienam. Não é ideia que se faça mito. É condição indispensável ao movimento de busca em que estão inscritos os homens como seres inconclusos. (FREIRE, 2005, p. 37).

Nosso educador tem uma leitura peculiar da liberdade, enquanto autonomia, com foco na ação e no compromisso com o mundo. Cabe destacar, que muito de sua compreensão de liberdade está ancorada, na leitura de Hegel, sobretudo, o Hegel da fenomenologia do Espírito, no qual a parábola do senhor e do escravo (HEGEL, 1997, p. 126) revela uma relação de sub-

\footnotetext{
${ }^{5}$ Essa parábola marca o pensamento de Freire, sobretudo, no que concerne que a liberdade e o reconhecimento se efetivam em meio a uma luta. É, portando, um esforço, é uma conquista e não uma doação, efetivada via um relacionamento entre o opressor e o oprimido, nas palavras de Hegel entre o senhor e o escravo. Nesta perspectiva vale conferir: Kojève (2002, p. 532) na qual ele expressa sobre a luta em fins do reconhecimento que: "Hegel especifica que o que importa nessa luta não é a vontade de matar, mas expor-se ao perigo de morte sem a necessidade, sem ser forçado a isso como um animal". É também esclarecedor a posição de Silva $(2008$, p. 85) quando afirma que: "Assim sendo, percebe-se que a elaboração do reconhecimento não constitui tarefa fácil(...) Cabe, contudo, esclarecer que reconhecer não é perder a identidade, mas passa, sem dúvida, pelo risco da vida ao se con-
} 
missão, luta e reconhecimento em que o segundo se vê no mundo mediatizado pelo primeiro, via reconhecimento. Para Freire reside aí um dilema a ser superado uma vez que o oprimido por vezes tem seu prisma de ser humano justamente na imagem distorcida de seu opressor. Assim, os riscos de reprodução das relações de opressão são eminentes. Desse modo, libertar-se implica libertar-se em dupla dimensão, isto é, primeiro: alcançar a liberdade na relação com o opressor e, em seguida, libertar-se do paradigma que guiava essa concepção, para que se alcance uma autonomia e está implique em transformação, pelo contrário, será reprodução.

Dito isto, temos que em Freire toda reflexão é fruto de uma experiência. Experiência sobre o mundo, com foco nas relações humanas e nas possibilidades de inovação, criação e manifestação. Freire é um pensador dos eventos. Para ele não tem sentido qualquer teoria que se desloque da realidade, do mundo vivido. Se a relação que se estabelece no mundo em questão é uma relação pautada no binômio opressor - oprimido, então a reflexão se encaminha nessa direção, nos esclarece ele:

A práxis, porém, é reflexão e ação dos homens sobre o mundo para transformá-lo. Sem ela, é impossível a superação da contradição, opressor - oprimido. Desta forma, está superação exige a inserção crítica dos oprimidos na realidade opressora, com que, objetivando-a, simultaneamente atuam sobre ela. Por isto, inserção crítica e ação já são a mesma coisa. Por isto também é que o mero reconhecimento de uma realidade que não leve a esta inserção crítica (ação já) não conduz a nenhuma transformação da realidade objetiva, precisamente, porque não é reconhecimento verdadeiro. (FREIRE, 2005, p. 42-43).

Entendemos que o binômio opressor - oprimido em Freire não é estanque e pode mobilizar diferentes leituras em diferentes contextos na qual o fenômeno da política seja central e a liberdade desponte como fundamental. Desse modo, o binômio tem importância heurística na obra de Freire e emerge como possibilidade analítica de primeira grandeza. Assim, pensar a liberdade a partir do binômio opressor - oprimido nos possibilita lê desde as relações do micro - poder no interior de uma sala de aula, as relações de confronto com o Estado, passando pelas relações de trabalho e traspassando as relações de expurgo político, tão presentes em nossos dias nos corpos de refugiados, indígenas, negros, Lgbts entre tantos outros.

Ensino que não visa o mundo, que não se compromete com o mundo, que não muda o mundo, não ama o mundo. Ensino para Freire só tem sentido de ser se considerar o mundo como objeto de ação, como lócus de vivência e como espaço da liberdade. O mundo é palco das relações humanas. É a rigor a quintessência da liberdade. Nenhuma liberdade metafísica é postulada pelo pensador em questão. A liberdade aqui se efetiva e se manifesta na ação, e não qualquer ação, mas uma ação sobre o mundo, no mundo, pelo mundo. Passa sim pela utopia, mas como dito antes não como quimera, mas pelo contrário, como forma de realizar o que ainda não foi realizado. A utopia não é aqui o consolo dos acomodados. Em Freire, a utopia é a esperança dos revolucionários. É busca, é caminho, é construção, é projeto, é a luta que se efetiva frente aos horrores da vida e às situações de opressão. Como nos ilumina o educador

É certo que mulheres e homens podem mudar o mundo para melhor, para fazê-lo menos injusto, mas a partir da realidade concreta a que "chegam" em sua geração. E não fundadas ou fundados em devaneios, falsos sonhos sem raízes, puras ilusões. O que não é, porém,

frontar com o outro". Ou nas palavras de Lima Vaz (2014, p. 61) “... a parábola insinua, remete à dialética da liberdade no reconhecimento da razão entre a identidade do ser (senhor) e a sua inexorável passagem pelo outro como diferença de si (escravo). (...) Essa parábola é a correspondência, no entrecruzamento da Razão e da liberdade do espírito, da relação entre metafisica (verdade) e Ética (bem) que marca a tradição mais cara da filosofia ocidental". Por fim, mas também ilustrativo dessa importante passagem sobre o "Senhor e o Escravo" temos a posição de Roberto Wu (2007, p. 252) quando afirma: "Trata-se, portanto, nessa busca pelo reconhecimento, uma luta de vida ou morte, na medida em que o indivíduo só pode se tornar o que ele é de fato por meio da conquista do reconhecimento de outro indivíduo". 
possível é sequer pensar em transformar o mundo sem sonho, sem utopia ou sem projeto. As puras ilusões são os sonhos falsos de quem, não importa que pleno ou plena e boas intenções, faz a proposta de quimeras que, por isso, mesmo, não podem realizar-se. A transformação do mundo necessita tanto do sonho quanto a indispensável autenticidade deste depende da lealdade de quem sonha às condições históricas, materiais, aos níveis de desenvolvimento tecnológico, científico do contexto do sonhador. Os sonhos são projetos pelos quais se luta. Sua realização não se verifica facilmente, sem obstáculos. Implica, ao contrário, avanços, recuos, marchas às vezes demoradas. Implica luta. Na verdade, a transformação do mundo a que o sonho aspira é um ato político e seria ingenuidade não reconhecer que os sonhos têm seus contrassonhos. (FREIRE, 2010, p. 293-294).

Se a transformação do mundo é um ato político, então não temos nem política nem ensino neutros, ressalva Freire (2010, p. 298). "A educação jamais pode ser neutra". Assim, sendo o ato de ensinar um tomar posicionamento, pode o ensino ser transformador ou reprodutor da realidade. Desse modo, nossa eticidade no mundo, determina se diante da opressão, escoIhemos compactuar com esta ou contra ela se opor. Para tanto precisamos, tanto educadores como cidadãos em geral nos encher de coragem, pois se temos que escolher um lado, e esse, é o dos oprimidos, precisaremos de coragem para defendê-lo e, como disse Arendt: "A coragem é indispensável porque em política, não a vida, mas sim o mundo está em jogo" (ARENDT, 2001, p. 203). Não cabe aqui nenhuma ideologia determinista, do tipo: "o mundo sempre foi assim, injustiças sempre existiram, querer mudar isso é tolice..." Se temos responsabilidade pelo mundo, o que implica compromisso também com as novas gerações e se, sobretudo, somos progressistas, "temos o dever de se opor a todo determinismo, de não aceitar ou estimular nenhuma postura fatalista" (FREIRE, 2010, p. 299).

Nesta pista, se temos um mundo precisamos e devemos nos comprometer com ele. Não por imposição fatalista ou determinismo histórico, mas por escolha que nossa eticidade no mundo nos permite. Assim, "se progressista estímulo e possibilito, nas circunstâncias mais diferentes, a capacidade de intervenção no mundo, jamais seu contrário, o cruzamento de braços em face dos desafios" (FREIRE, 2010, p. 300).

Desse modo, todo ensino e, sobretudo, o ensino de filosofia deve ser um compromisso com o mundo a partir de uma reflexão que induza a ação. Sem isso estaremos no terreno da mera especulação e transmissão de informação sem formar para a cidadania. Por cidadania entendemos o compromisso com a vida política com a pertença a uma comunidade e compromisso com esta, a partir de direitos e deveres. Assumindo as palavras de Aguiar (2006, p. 281282) "Cidadania enquanto direito a ter direitos, pois somos cidadãos livre e capazes de julgar".

\section{Hannah Arendt: a educação como amor mundi}

É preciso ter claro, que Hannah Arendt não foi uma pensadora que tomou a educação como objeto de pesquisa. Ela, não se via como uma educadora stricto senso. Suas preocupações orbitam em torno do fenômeno da política e a esse tema dedicou sua vida acadêmica. Todavia, textos como: A crise na educação [1957] ${ }^{6}$ e reflexões sobre Little Rock [1959] ${ }^{7}$ refletem o olhar da pensadora sobre o tema da educação. Esses textos podem ser tomados como escritos de cir-

\footnotetext{
${ }^{6}$ The crisis in Education foi pela primeira vez publicado na Partisan Review, 25, 4 (1957), pp. 493-513. Também foi publicado em alemã em FragwürdigeTraditionsbestände im Politischen Denken der Gegenwart, Frankfurt:Europäische Verlagsanstalt, 1957. Posteriormente, o texto veio a ser reimpresso na coletânea Between Past and Future: Six Exercises in Political Thought, New York: Viking Press, 1961, p. 173-196.

7 Este artigo foi publicado a primeira vez na Revista Dissent, 1(6), 45-56 de 1959 e posteriormente no livro organizado por Jerome Konh "Responsibility and judgmente" [2003].
} 
cunstância, todavia, não são desconexos de sua visão política, sobretudo, no que concerne uma reflexão sobre responsabilidade com o mundo ou amor mundi. Assim, suas reflexões nessa área, não estão dissociadas do todo de sua obra.

Ao tratar da relação entre política e educação e da ligação destes para com o mundo, Arendt assume um olhar reflexivo que visa compreender os eventos de sua época. A pensadora nos conclama a um modo de entender a filosofia e suas dimensões inclusive a do ensino, como prática de cada época, isto é, de cada presente que desafia nosso entendimento. Assim, olhar para o presente, ainda que iluminado pelo passado, tendo a permanência do mundo como fundante para o existir em comunidade.

Aqui, ao assumirmos tal empreitada, pensamos estar trilhando os passos de Arendt de forma coerente, pois consideramos que esta foi uma preocupação sua no decorrer de seu desenvolvimento teórico. Nossa pretensão ao enfrentar tal questão se firma no espírito arendtiano de busca e não de fórmulas prontas como fez a tradição, por isso nosso empenho, no intuito de responsabilizar-se pelo mundo via educação, assume a metáfora da trilha e não do trilho.

O trilho é composto de caminhos definidos, de fim último estabelecido. Situação semeIhante à da tradição metafísica, que busca o fundamento último de todas as coisas. Ao contrário do trilho, engessado e repleto de definições prévias, optamos pela trilha que propõe como segurança, a busca. Assim, nossa compreensão reside no fato de que se a responsabilidade pelo mundo for uma trilha, temos como única coisa definida nossa existência, via perenidade da natalidade, que traz consigo a marca potencial da política. "Além disto, como a ação é a atividade política por excelência, a natalidade, e não a mortalidade pode constituir a categoria central do pensamento político, em contraposição ao pensamento metafísico", assevera Arendt (ARENDT, 2019, p. 11).

Desse modo, educação em Arendt representa um comprometer-se com o mundo. Esse compromisso se efetiva via reflexão e a ação sobre o mundo, buscando dar a ele uma permanência, na medida em que ele nos abriga e nos acolhe enquanto realidade natural e nos interpõe sentido, enquanto artifício produzido. De modo que protegê-lo em sua mundanidade torna-se nossa tarefa política fundamental. Desta feita, trilhar o significado da responsabilidade pelo mundo não significa saber onde se vai chegar, mas buscar construir espaços de atuação, em nome da permanência daquilo que se encontra historicamente ameaçado, já que para Arendt o conceito de mundo emerge não a partir do clássico recuo contemplativo do filósofo em relação ao cotidiano dos assuntos humanos, mas sim a partir da concretude dos acontecimentos políticos e dos "incidentes da experiência viva" (ARENDT, 2001, p. 44).

O mundo em Arendt é o espaço artificial entre o homem e a natureza, bem como âmbito intermediário de relacionamento e distinção instaurado entre os homens por meio de suas interações e interesses comuns. O mundo é tudo aquilo que, aparecendo a todos e sendo comum aos homens, deve a sua existência ao arranjo total dos cuidados humanos ou das diferentes atividades empreendidas pelo homem. O mundo serve de assunto entre os homens e de abrigo estável não-natural instaurador de fronteiras que protegem e distinguem a presença humana do movimento circular e homogêneo da natureza, responsável pelo ciclo de vida e morte das gerações. (NETO, 2009, p. 19)

Assim, ao nos depararmos com a afirmação de Arendt sobre a feição política desse enfrentamento enquanto responsabilidade pelo mundo, entendemos, e ousamos afirmar, que ao lado desta emerge o papel da educação. A educação, ainda que pré-política, em vista de sua condição relacional de desiguais, guarda em si forte diálogo com a política (SILVA, 2012, p. 393). Sobretudo, se considerarmos a lúcida interpretação de Duarte $(2013$, p. 39) que ressalva que o 
modo de pensar de Arendt mobiliza pares conceituais, não como conceitos estanques, mas, ao contrário, são tomados na perspectiva da fina arte de distinguir e relacionar conceitos.

Assim sendo, esse diálogo entre política e educação, toma o mundo como palco dos negócios humanos e lócus de sua teia de relações, nele as futuras gerações ganham sentido de permanência. Assim, o ato de ensinar vai além se Joãozinho sabe ou não sabe lê, assevera Arendt (2001, p. 227).

Uma vez que a política e a educação têm em seu exercício a condição privilegiada de assumir esse amor-mundi, que significa responsabilidade pelo mundo, também afirma junto a estas futuras gerações: este é o nosso mundo. (cf. ARENDT, 2001, p. 239). Nesta perspectiva, a competência educacional não se restringe ao ensino como técnicas de aprendizagem, mas encontra-se gestada de sentido político na medida em que pais e educadores passam a ter uma função muito maior junto às crianças e junto ao espaço de permanência destas. Assim, "eles assumem na educação a responsabilidade, ao mesmo tempo, pela vida e desenvolvimento da criança e pela continuidade do mundo." (ARENDT, 2001, p. 235).

Nesta pista, do mundo a ser protegido e do novo que o adentra - a criança -, estamos inseridos em uma "fenomenologia de fronteira", isto é, uma constante tensão daquilo que se apresenta. Esta tensão emerge entre duas realidades que, paradoxalmente, necessitam uma da outra e, ao mesmo tempo, carecem de proteção mútua. Assim sendo, a educação cumpre um papel inicial de guarida de um novo ser - a criança. Esta não pode ser atingida por nada de negativo ou destrutivo do mundo, todavia, esse mundo que emerge como lócus da permanência, também precisa de proteção diante do assédio do novo que se irrompe a cada geração. (Cf. ARENDT, 2001, p. 235)

Quando destacamos a novidade que a criança representa, significa dizer consoante Arendt que "a criança só é nova em relação a um mundo que existia antes dela" (ARENDT, 2001, p. 285). Isto implica diretamente uma condição política velada sob o aspecto da permanência. Haja vista que para esse novo [a criança] encontrar o já existente [o mundo] implica em uma relação de proteção e permanência.

Desse modo, o mundo, carece de durabilidade institucional e natural que precisa ser constantemente garantida para que esse encontro possa se efetivar pelo menos em três formas fundamentalmente necessárias, a saber: i) na natalidade, que vem à tona como essência da educação (ARENDT, 2001, p. 223), ii) na ação e no discurso, que emergem como significado da liberdade, condição privilegiada da política e da garantia dos negócios humanos, e, por fim, iii) na política enquanto ocupação do espaço público capaz de fundar memória e buscar direitos que protejam o mundo também em sua dimensão natural ${ }^{8}$. Tal constatação da necessidade de proteção do mundo nos conduz à reflexão em torno da maneira de como estamos nos relacionando com os recursos naturais e com as garantias de se movimentar livremente nos assuntos humanos.

Sendo Arendt uma pensadora do Evento, isto é, uma intelectual disposta a compreender o seu presente, tem nisso uma pedra de toque com Freire. Ambos os pensadores entenderam que pensar e agir sob as condições dadas de sua existência presente era algo de primeira ordem. Nesse sentido, em ambos os casos, A educação é vista como uma forma de estar no mundo hoje de transformá-lo no presente, em vista da constituição de uma comunidade permanente para os novos que se irão chegar e chegam a todo instante.

\footnotetext{
${ }^{8}$ Em nosso tempo, nenhuma forma de ensino, pode deixar de lado a questão ecológica. O mundo das relações - o estar entre de Arendt - deve ser preservado com suas instituições e negócios humanos. Na mesma medida, o mundo natural.
} 
Assim, tendo a amor - mundi como perspectiva, Arendt toma a categoria da responsabilidade como central. Novamente temos outra interseção que pode ser ligada com o pensamento de Freire. Em ambos intelectuais não é o método o cerne da questão. Embora em Freire, o método seja de uma relevância ímpar, sua teoria não fica nele ${ }^{9}$, como antes falado visa a transformação do mundo, pois o Ensino implica em dignidade humana para além da alfabetização, não contra ela, mas além dela. Educação em Arendt tem essa dimensão de responsabilidade para além do aprender a ler, pois é preciso ler o mundo, isto é, compreendê-lo.

Ao nosso entendimento, temos na liberdade o maior ponto de aproximação entre Freire e Arendt. Respeitado as especificidades, ambas compreensões se encontram no entendimento de uma liberdade que tem a ver com o pleno exercício de fala, de participação de aparição no interior de uma comunidade. Em ambos pensadores as singularidades devem emergir no seio do espaço público. Nessa perspectiva, tudo que possa obstar essa liberdade deve ser combatido.

Por isso, as violências e os autoritarismo não encontram ressonância nem nos processos de ensino ou da educação, como também não encontram guarida nos espaços de deliberação do pleno uso fruto da política. Tanto Freire como Arendt visam uma educação republicana, na qual o interesse e a felicidade pública assumem a centralidade. Sobre isso, nos esclarece Brayner (2008, p. 38) uma educação republicana é aquela capaz de garantir a visibilidade no espaço público tendo em vista a maior integração a comunidade e evitando a exclusão.

Freire, por sua vez, defende a liberdade como bem maior. Uma liberdade que se efetiva na existência plural dos seres humanos, garantindo a todos, sua dignidade, independentemente de cor, sexo, classe social ou etnia. Nos ajuda nessa aproximação as palavras de Albuquerque (2010, p. 147) “A luta pela educação pública popular e democrática configura-se, assim, como categoria histórica fundamental" uma educação que faz do outro um sujeito querido, respeitado, amado. Em última instância que toma o outro como legitimo outro, como cidadão que tem direito a ter direitos.

\section{Considerações finais}

Exposto isto, temos que em Arendt e Freire [A educação] o ensino sempre é compromisso com o mundo, com a justiça e com a felicidade pública. Não intenciona seus pensamentos serem reduzido à alfabetização, mas passando por essa importante etapa, visa à vida política, a ocupação do espaço público.

Neste sentido, educar para o bem, para o justo e, para o belo, visando o melhor para a comunidade parece-nos uma pedra de toque com o que pensou Freire e o que Arendt compreendeu, ao sugerir responsabilidade com o mundo. Nesta direção, Arendt indica que a educação se liga a um amor mundi (ARENDT, 2001, p. 247) enquanto cuidado e preservação deste. Claro que estamos cônscios dos limites destas aproximações, a fazemos apenas no intuito de esclarecer que o pensador da educação brasileira estava atento tanto a tradição do pensamento filosófico como ao que Arendt tinha proposto e ele absorveu e se aproximou sem deixar de manter sua perspectiva própria. Assim, Arendt e Freire se revelam agudos, atuais e necessários pensadores do mundo hodierno, por entenderem que ensinar nos conduz a enfrentamentos marcados pelo proceder ético, pedagógico e político diante do mundo.

\footnotetext{
${ }^{9}$ A experiência de alfabetização em Angicos-RN, realizado por Freire, revela isso. Ao alfabetizar os camponeses e colocá-los em contado com as letras foi um importantíssimo passo. Todavia, não significava apenas isto. Ao apresentar a palavra tijolo e estabelecer seu significado semântico, linguístico e gramatical, também se indagou: o tijolo serve para construir casas? Então, por que muitos não têm onde morar? Esta pergunta vai além de decodificar fonemas, ela se insere na leitura de mundo, no despertar de uma consciência crítica, capaz se entender a própria realidade e lutar por esta.
} 
Nesta pista, Freire nos adverte para a difícil e estimulante resistência dos movimentos sociais. Estes movimentos são para o pensador tanto experiências éticas como pedagógicas (FREIRE, 2010, p. 301). Nossa história, está repleta destes movimentos de resistência; a rebeldia dos quilombos, as lutas das ligas camponesas, o movimento dos sem-terra, entre outros, nos lembra Paulo Freire.

Hoje podemos ainda acrescentar que essa luta se amplifica na resistência dos sem teto, da juventude pobre e negra das periferias, dos Lgbts das mulheres feministas que se opõem ao machismo e a misoginia. Em todas essas expressões de resistência, nos inspira Freire; impera uma necessidade de luta.

Ao tratar de cada resistência como ato político e pedagógico, o pensador põe em relevo que cada uma dessas lutas "No fundo, jamais se entregariam à falsidade ideológica da frase: "a realidade é assim mesmo, não adianta lutar, ao contrário, apostaram na intervenção do mundo" (FREIRE, 2010, p. 301).

Posto isso, entendemos ter apresentado, ainda que de maneira sumária, a perspectiva de Hannah Arendt e Paulo Freire como pensadores que ao focar na educação e no ensino foram para além do letramento, e entenderam estes, como comprometimento e responsabilidade com o mundo, perspectiva que, ao nosso entender, deve ser a de todo ensino de filosofia, isto é, de cuidado e responsabilidade pelo mundo.

\section{Referências bibliográficas}

ALMEIDA, Vanessa S. Amor mundi e Educação: reflexões sobre o pensamento de Hannah Arendt. 2009. 193p. Tese (Doutorado em filosofia). Universidade de São Paulo. 2009.

ALBUQUERQUE, Targélia de S. Gestão Paulo Freire: A ousadia de democratizar a "educação na cidade de São Paulo (1989- 1991). In: INÊS, Ana. (Org). Paulo Freire: Vida e Obra. São Paulo: Expressão Popular, 2010.

ALVES NETO, Rodrigo Ribeiro. Alienação do Mundo: uma interpretação da obra de Hannah Arendt. São Paulo: Ed. Loyola /PUC-Rio, 2009.

AGUIAR, Odílio Alves. Direitos humanos como "direito a ter direitos" em Hannah Arendt. In: AGUIAR, Odílio Alves et. al. (Orgs.). Filosofia e Direitos humanos. Fortaleza: Ed. UFC, 2006.

ARENDT, Hannah. A vida do Espírito. Trad. Cesár Augusto de Almeida et. al. Rio de Janeiro: Ed. Cia das Letras, 2009.

ARENDT, Hannah. Entre o passado e o futuro. Trad. Mario W. Barbosa. São Paulo: Ed. Perspectiva, 2001.

ARENDT. Hannah. A condição Humana. Trad. Roberto Raposo. $13^{a}$ edição. Rio de Janeiro: Forense Universitário, 2019.

DUARTE, André. Hannah Arendt e pensamento político: a arte de distinguir e relacionar conceitos. Revista Argumentos. Fortaleza, ano, 5, no. 9, jan/jun 2013. Disponível em: http://www. periodicos.ufc.br/argumentos/article/view/19001/29720. Acesso em: 20. Mai.2020.

FREIRE, Paulo. Pedagogia da Autonomia: saberes necessários à prática educativa. Rio de Janeiro: Ed. Paz e Terra, 1999.

FREIRE, Paulo. Pedagogia do Oprimido. Rio de Janeiro: Ed. Paz e Terra, 2005.

FREIRE, Paulo. Carta do direito e do dever de mudar o mundo. In: SOUZA, Ana Inês. (Org.). Paulo Freire: Vida e obra. São Paulo: Ed. Expressão Popular, 2010. 
FREIRE, Paulo. Pedagogia da Esperança: um reencontro com a pedagogia do oprimido. Rio de Janeiro: Ed. Paz e Terra, 1992.

FIORI, Ernani Maria. Aprender a dizer a sua palavra [Prefácio]. In: FREIRE, Paulo. Pedagogia do Oprimido. Rio de Janeiro: Ed. Paz e Terra, 2005.

HEGEL, G.W.F. Fenomenologia do Espírito. Trad. Paulo Meneses. 3a ed. Petrópolis: Editora Vozes,1997.

LIMA VAZ, Henrique Cláudio. A formação do pensamento de Hegel. São Paulo: Ed. Loyola, 2014.

PLATÃO. Apologia de Sócrates. São Paulo: Editora nova Cultural, 1999. (Coleção Os Pensadores).

PLATÃO. A República. Trad. Maria Helena. Lisboa. 3ª ed. Lisboa: Ed. Calouste, 1980.

WU, Roberto. Do desejo ao reconhecimento: a luta pela afirmação da autoconsciência. In: CHAGAS, Eduardo et. al. (Org.). Comemoração aos 200 anos da "Fenomenologia do Espírito" de Hegel. Fortaleza: Ed. UFC, 2007.

RODRIGO, Lídia Maria. Filosofia em sala de aula: teoria e prática para o ensino Médio. Campinas: Ed. Autores Associados, 2009. (Coleção Formação de Professores).

SILVA, Ricardo George de A. Educação e Responsabilidade pelo mundo: reflexões em torno do pensamento arendtiano. In: AGUIAR, Odílio Alves et. al. (Org.). O futuro entre o passado e o presente: anais do V encontro Hannah Arendt. Passo Fundo: IFIBE, 2012.

KOJÈVE, A. Introdução à leitura de Hegel. Rio de Janeiro: Ed. Contraponto, 2002.

Sobre o autor

Ricardo George de Araújo Silva

Doutor em Filosofia. Professor do curso de Graduação e do Mestrado Acadêmico em Filosofia da Universidade Estadual Vale do Acaraú (UVA). Professor colaborador do Mestrado Profissional em Filosofia da UFC [PROF-FILO-UFC]. Editor da revista de Filosofia Reflexões, disponível na web em: www.revistareflexoes.com.br 